\title{
GÊNERO COMO FORMA DE VIR A SER: UMA ANÁLISE DO LIVRO A CIÊNCIA JURIIIICA E SEUS DOIS MARIDOS FRENTE À EDIFICAÇ̃̃O DE UM PENSAR COMPLEXO NO DIREITO
}

\author{
GENDER AS A WAY TO BECOME: AN ANALYSIS OF THE BOOK THE JURIDICAL SCIENCE AND THEIR TWO \\ HUSBANDS FACING THE EDIFICATION OF A COMPLEX THINKING INLAW
}

\section{RESUMO}

No presente estudo, através da imaginação literária provocada pela obra $A$ ciência jurídica e seus dois maridos, de Luis Alberto Warat, convida-se o leitor a um pensar complexo no Direito, a partir da necessidade da dialética entre sensibilidade e razão. No imaginário surrealista, problematiza-se uma visão cartesiana, dogmática e fechada, questionando-se o gênero como uma categoria de vir a ser. A pergunta norteadora é: seria o gênero uma possibilidade de abertura, de descentramento, de um devir ambivalente? Desse modo, a partir de uma abordagem complexo-paradoxal, problematizam-se as ambiguidades que são inerentes ao ser. Conclui-se que gênero, em um viés simplista/dicotômico, deriva da poda de um desejo, de um devir castrado por uma ideologia cartesiana, de uma racionalidade centrada, logocêntrica; por outro lado, a visão de gênero como vir a ser abre a perspectiva do vazio, do abrir-se a novas perspectivas do vir a ser complexo e paradoxal.

Palavras-chave: Gênero. Complexidade. Castração. Surrealismo. Ambivalência.

\begin{abstract}
In the present study, through the literary imagination provoked by the work Legal Science and its two husbands, by Luis Alberto Warat, the reader is invited to a complex thinking in Law, based on the need for the dialectic of sensitivity and reason in law. Within the surrealist ideal, a Cartesian, dogmatic and closed view is problematized, as questions raised on gender as a category of becoming. The guiding question is:

\footnotetext{
Noli Bernardo Hahn

Pós-doutor pela Faculdades EST. Doutor em Ciências da Religião, Ciências Sociais e Religião, pela UMESP. Professor Tempo Integral da URI, Campus de Santo Ângelo. Graduado em Filosofia e Teologia. Possui formação em Direito. Integra o Corpo Docente do Programa de Pós-Graduação Stricto Sensu - Mestrado e Doutorado em Direito. Lidera o Grupo de Pesquisa Novos Direitos em Sociedades Complexas, vinculado à Linha 1, Direito e Multiculturalismo, do PPG Mestrado e Doutorado em Direito da URI. Pesquisa temas relacionando Gênero, Direito, Cultura e Religião. E-mail: nolihahn@san.uri.br Bianca Strücker

Acadêmica do Curso de Doutorado em Direito do Programa de Pós-Graduação em Direito da Universidade Regional Integrada do Alto Uruguai e das Missões - URI, pesquisadora bolsista da CAPES, advogada. E-mail: biancastrucker@hotmail.com

Thaís Maciel de Oliveira

Acadêmica do Curso de Doutorado em Direito do Programa de Pós-Graduação em Direito da Universidade Regional Integrada do Alto Uruguai e das Missões - URI, pesquisadora bolsista da CAPES, advogada. E-mail: adv.thaismaciel@gmail.com
} 
would gender be a possibility of openness, of decentralization, of an ambivalent becoming? Thus, from a complex-paradoxical approach, the ambiguities that are inherent to being are problematized. It is concluded that gender, in a simplistic/ dichotomous bias, derives from the pruning of a desire, from a castrated becoming by a Cartesian ideology, from a centered, logocentric rationality, as the vision of gender becomes open to the perspective of emptiness, of opening up to new perspectives of becoming complex and paradoxical.

Keywords: Gender. Complexity. Castration. Surrealism. Ambivalence.

\section{Introdução}

O pensamento contemporâneo do Direito consagra-se por seu positivismo científico, isto é, por sua tradição positivista como visão científica da ciência. Como um suposto legado dos rompimentos teleológicos, a racionalidade se define como o logos não advindo de um pressuposto teocêntrico, mas na razão humana, do pensamento moderno calculador. Assim, a superação do mito pelo lógos pautou-se em uma desconstrução do dado pelo criado. Jacques Derrida (2017, p. 3-6) aborda esta temática em Gramatologia, quando diz que há a necessidade de se combater o imperialismo do lógos, pois este comanda, também, o conceito de escritura, de ciência e toda a cientificidade da ciência e a história da metafísica. Derrida dessedimenta o imperialismo do lógos, ao combater as alienações da linguagem.

No plano da hermenêutica, o sujeito moderno do direito não rompeu com o plano da metafísica, se reificando uma essência paradigmática, em busca de uma realidade que se tornou singular e mundana. Com efeito, o paradigma aristotélicotomista busca o logos do universal e do abstrato. Nesse enfoque, a ciência e a linguagem partem de uma molécula do conhecimento que o sujeito analisa o objeto, parte de uma molécula do conhecimento dicotômica, platônica, de separação e análise externa.

Diante da crise da hermenêutica no judiciário e das extensas decisões discricionárias dos juízes, ministros e colegiados, a questão moral da lei é tema recorrente em estudos e produções científicas. Frente ao aspecto amplo da lei, a discricionariedade dos juízes molda-se como forma de superar essa lacuna. Entretanto, esse positivismo normativo revela decisões e compreensões morais de julgadores solipsistas e totalitários. Eis que o sentido político da linguagem se infere no direito, como fonte originária e logocêntrica. $\mathrm{O}$ direito e a linguagem como matrizes mesmas inferem no modo de pensar, logo sua tradução conduz ao aspecto simbólico do seu lugar de fala. O julgador sob o aspecto discricional e neutro é edificado por bases logocêntricas e de racionalidade centrada. Assim, esse julgador solipsista fala o direito a partir de um viés metafísico e deontológico, a partir de suas próprias convicções, produzindo o conhecimento científico a partir de sua mesmidade e castração. 
Frente à instabilidade dos recentes julgados no Direito sob o viés político, a ânsia de pesquisar a desconstrução do sujeito solipsista é em decorrência da necessária segurança jurídica para a concretização de um Estado Democrático de Direito e concretização de um espaço democrático integrador e descentrado. É inegável o legado que a modernidade trouxe para a ciência do direito, entretanto a necessidade de novos paradigmas é primordial face a um direito contemporâneo e complexo. Desse modo, pretende-se sair do caráter especulativo e adentrar ao caráter hermenêutico, empírico-linguístico no lugar de fala no Direito. Assim, problematizase a razão vulgar em face de seu pressuposto hegemônico, ou seja, questiona-se a indiferença constituinte no direito, diante de seu discurso de proliferação de si mesmo.

Em A Ciência Jurídica e seus Dois Maridos, livro presente no primeiro volume da coletânea de textos waratianos nomeada como Territórios desconhecidos: a procura surrealista pelos lugares do abandono do sentido e da reconstrução da subjetividade (2004), Luis Alberto Warat apresenta a dicotomia e a ambivalência através dos dois maridos de Dona Flor. A personagem Dona Flor, que representa a ciência jurídica, tem uma ambivalente necessidade de estabelecer seus vínculos afetivos simultaneamente no lugar de prazer e dever. O personagem Vadinho representa o prazer, e Teodoro representa o dever, vítima de uma cultura que totaliza, fecha e estereotipa os seres. Teodoro seria uma metáfora do homem reprimido, castrado, enquanto Vadinho é a metáfora da espontaneidade, da paixão. Warat (2004), então, passa a argumentar acerca da necessidade de recuperar a poesia que foi reprimida pela cultura e a espontaneidade diante dos estereótipos.

Dona Flor, por outro lado, é protagonista e heroína, ambígua, apresentada face a suas características éticas e morais. Warat interliga a obra literária ao direito, como forma de problematizar a necessidade da dialética da sensibilidade e da razão. No imaginário surrealista, Warat propõe pensar o direito, problematizando uma visão cartesiana, dogmática e fechada. Neste contexto, questiona-se o gênero como uma categoria de vir a ser, seria o gênero uma possibilidade de abertura, de descentramento, de um devir ambivalente?

Através da abordagem metodológica complexo-paradoxal, a fim de não simplificar o olhar e conseguir alcançar as ambiguidades existentes em cada reflexão, primeiramente, objetiva-se abordara ambiguidade da lei e do lúdico, buscando compreender o pensamento waratiano, por meio de um olhar atento para a obra $A$ Ciência Jurídica e seus Dois Maridos, pontuando as metáforas existentes nas sombras de cada personagem. Num segundo momento, o pensamento carnavalizado de Warat é contrastado com a formulação de verdades absolutas, para pensarmos em verdades históricas e contextuais. Por fim, utiliza-se a compreensão do feminino, como noção de gênero, com o intuito de apresentar um porvir, uma abertura, um verdadeiro olhar ao Outro. Assim, analisando a realidade como modo de vir a ser, o sujeito desconstrói suas totalidades como forma de se abrir a uma visão ontoepistemológica e metodológica complexa. Aqui, direito e ficção conjugam-se por 
serem termos da criação humana. Deste modo, o presente estudo convida o leitor a pensar gênero de forma complexa e aberta.

\section{Warat e o romance sobre a ambiguidade da lei e do lúdico}

A literatura pode contribuir com o Direito em muitos aspectos, retirando-o das páginas dos códigos, das togas, das limitações em que fora posto pelo positivismo e pela dogmática, bem como conceder-lhe uma nova sensibilidade capaz de lhe devolver a vida. Em A ciência jurídica e seus dois maridos ${ }^{1}$, Luis Alberto Warat nos demonstra justamente este propósito ao narrar as problemáticas do Direito e a existência de soluções para estas, isto é, retrata a crise na relação entre a Ciência Jurídica e a falta de uma razão sensível no direito.

Warat denuncia a epistemologia moderna, perante o seu logocentrismo pautado na razão em detrimento do outro, do diferente, da sensibilidade ${ }^{2}$. $\mathrm{O}$ autor argumenta que o primado da razão levou à construção de um ser autoritário e intolerante, um ser castrado pelo humanismo moderno. Nesse sentido, a obra literária representa, no imaginário do direito, a grande dialética da razão e da sensibilidade.

Esse espaço da ambivalência da ordem e da desordem, que a análise literária propõe, questiona as crenças instituídas diante de um paradigma científico castrador. Assim, a castração significa a objetificação dos seres e sua totalização diante da cultura do imobilismo. Dessa forma, o imaginário proposto através dos três personagens da obra representa a ambiguidade que é inerente ao ser.

Nesses termos, Dona Flor, como heroína da ambiguidade, é um indivíduo instituído. Dona Flor se emancipa das verdades absolutizadas para viver intensamente, ou seja, nas palavras de Warat, Dona Flor "resiste ao poder de castração de toda psicologia da unidade" (WARAT, 2004, v. 1, p. 62). Em função disso, a personagem rompe com a totalidade, desconstrói dicotomias em busca de verdades relativas, cria as suas próprias verdades. Desse modo, a personagem representa o imaginário erotizado, a saída do senso comum e o gozo despido de dogmatismos.

O saber, nesse sentido, significa rompimento, abertura, desconstrução ,emancipação. Para Warat, “a proposta do pensamento crítico pode

1 A obra faz uma metáfora do clássico de Jorge Amado, Dona Flor e seus Dois Maridos, e utiliza-se das características e personalidades dos principais personagens, Dona Flor, Vadinho e Teodoro, para traçar um comparativo com o direito e o saber jurídico.

2 Derrida relaciona etnocentrismo e logocentrismo e afirma que o logocentrismo é "o etnocentrismo mais original e mais poderoso, que hoje está em vias de se impor ao planeta, e que comanda, numa única e mesma ordem" (DERRIDA, 2017, p. 3-7) o conceito da escritura, a história da metafísica e o conceito da ciência ou da cientificidade da ciência. Ao relacionar etnocentrismo com logocentrismo o filósofo "parece dizer-nos que sua obra poderá (ou deverá?!) ser lida, como um todo, relacionando-a ao componente político da desconstrução, mesmo aqueles textos de rigor filosófico e estritamente filosóficos" (HAHN, 2018, p. 81).

3 Ao utilizar a linguagem e a metodologia por detrás do olhar desconstrutivista, Warat apela a Jacques 
apresentar-se como uma tentativa epistemológica diferente" (WARAT, 2004, v. 2, p. 27), de maneira que o saber jurídico crítico tenta estabelecer uma nova formulação epistemológica sobre o saber jurídico institucionalizado que, até então, é envolto por uma concepção sacralizada.

Dona Flor e seus dois maridos constituem-se, através da narrativa literária, personagens da realidade, integrados em uma cultura reducionista, mas, no caso de Vadinho, representa uma possibilidade de emancipação e rebeldia. A castração que o casamento com Teodoro simboliza consiste em uma representação do amor, da estereotipação do desejo e do amor, é o desejo representado. Nesse aspecto, através da dialética dos personagens repletos de ambiguidades, Warat argumenta sobre a cultura do imobilismo que aprisiona os indivíduos em objetos dessa consciência representada, fechada, totalitária.

A gênese da castração é uma gênese de dominação. Qualquer dominação começa por proibir a linguagem que não está prevista e sancionada. Quadro dramático, quadro dogmático, que bem define como capador-capado o campo do imaginário instituído: jurídico, educacional, científico, amoroso ou cotidiano. É o imaginário onde se produz um frágil equilíbrio entre castrações e sublimações e que faz crer que, quebrado esse equilíbrio, o homem tende ao autoritarismo. Nesse sentido, o discurso jurídico serve para fazer crer que há menos autoritarismo (WARAT, 2004, v. 1, p. 64).

Deste modo, a castração pode ser vista como uma rede de condenações a tudo aquilo em que o homem pode encontrar sua autonomia, um encontrar-se, como o amor, a sensibilidade, o sexo, o corpo. Logo, a castração simboliza a totalização em torno de si mesmo, um fechamento sobre si, o ápice da consciência representada. A castração caracteriza a negação do vazio, em virtude do ser estar pleno de si. Assim, despojar-se das verdades absolutas significa abertura ao vazio erótico, significa romper com a cultura do imobilismo que apregoa a negação do vazio. Consequentemente, a castração, como símbolo do sonambulismo contemporâneo, eterniza os seres em uma subvida contemporânea, em uma liquidez e efemeridade de sentidos e significações.

O casamento de Dona Flor com Teodoro representa o cerceamento do diálogo a ascensão do conflito, o quotidiano militarizado, a burocratização do amor; assim, o abrir-se para o autoritarismo é o desejo racionalizado. Significa o abrir-se para o espaço público sem voz, sem pluralidade, sem diferença. Nesse sentido, significa democracia sem voz, democracia sem espaço público, democracia sem plural.

A figura de Vadinho, nesse contexto, apresenta-se como um porvir aberto, personagem marginal, solto, advindo do inesperado, não totalizado, não reduzido

Derrida, filósofo que nasceu na Argélia, estudou em Paris e lecionou em diversas universidades europeias e americanas. Assim, Warat (2004, v. 2: 109) dialoga com Derrida para apontar a simbolização democrática com a dinâmica do descentramento, de pensar para além de uma ontologia totalizadora. 
a um mesmo. Vadinho simboliza as verdades relativas, o imaginário carnavalesco, o lúdico, o desejo despido, a sensibilidade. A ambiguidade de Vadinho e Teodoro representa a dialética necessária do viver, luz e escuridão, a dialética entre a razão e a sensibilidade. Dito de outro modo, na era da individualização e da totalização, a redução do Mesmo ao Outro determina todos os sentidos dos seres. Assim, a totalização dos indivíduos os condiciona a seres incompletos e infelizes. Consequentemente, é preciso que o Eu saia das amarras ontológicas da racionalidade e contemple o Outro como forma de alteridade e completude humana.

Em função disso, o vazio erótico que Vadinho representa, significa sair da racionalidade centrada, romper os dogmas, as verdades universais; significa a libertação da castração simbólica para um plural de significações. Sair da castração, portanto, é o abrir-se ao devir, ao novo, ao diferente, ao plural. Contrariamente, a castração desses espaços, como o matrimônio e a sociedade, pode implicar no cerceamento de seu espírito livre, mas, se emergirem de uma racionalidade descentrada, diferente, de um logos não originário metafísico, pode significar uma abertura, processos de encontros, de devires, de emancipações.

Dona Flor, ao suportar as tentativas da castração, segue em um porvir aberto, como uma heroína da ambivalência, simbolizando aquela que foge do dever, do dogmatismo e abre horizontes ao desejo (WARAT, 2004, v. 1). Esta abertura ao desejo é capaz de romper barreiras, classes, cores, sexualidades, o sentido totalitário das definições. "Flor soube misturar com orgulho as contradições, para ultrapassar suas próprias acomodações. Verdades menos garantidas, relações mais frutíferas" (WARAT, 2004, v. 1, p. 68). Dona Flor simboliza a abertura para a paradoxalidade, para as contradições, é a representação da pluralidade, dos horizontes, das verdades.

O diálogo, nesse sentido, é uma forma de realização da democracia, em virtude da democracia ser a procura de confrontos, de conflitos, ser diferença, ser procura e não resposta, democracia é inquietação. A obra literária Dona flor e seus dois maridos representa a ambiguidade do diálogo, representa o nascimento do diálogo do instituído, do concreto e do marginal, do livre, do diferente. A dialética da marginalidade caminha ao rompimento da castração, à liberação da nudez, do erotismo, do desejo, contra a censura da moral, convida para um modo de vir a ser aberto e complexo.

Warat postula que os dogmas das verdades inquestionáveis, das verdades absolutas, fechadas são mantidos e reiterados através da semiologia dominante, que através de sua linguagem metafísica reitera e reifica a linguagem, estabelece padrões e hierarquias. Nesse aspecto, o ser humano se enquadra e se coisifica em um modelo de ser fechado e fixo. Vadinho, contrariamente a essa lógica metafísica, confronta e recusa-se a ficar fixo, aprisionado neste mundo previsível e aprisionador dos desejos.

Nesses termos, a pedagogia marginal representa a recuperação da significação desejante, representa a construção de uma semiologia descentrada, que parte das diferenças, que abraça o erótico, a nudez. Na ambivalência, há o desejo, erotismo e sangue pulsante evivo. Em conformidade, a pornografia, como a castração dos desejos, a coisificação do eros pela sociedade do consumo, da aparência, é desconstruída a 
partir do erotismo marginal. Dona Flor, nesse sentido, consegue caminhar através da dialética entre erotismo e censura, entre prazer e dever.

Erotizar a vida, abrir-se ao novo e o diferente, é um caminho para a reflexibilidade da ciência na construção de um eterno devir humano. Warat argumenta que, para a construção de uma linguagem democrática jurídica, é necessário edificar mecanismos de transgressões de censuras. Nessa premissa, o erotismo precisa dessa dialética, do jogo das duas formas; a tese precisa formar-se da relação com a antítese. Assim, o estado, grande criador de aparências, é responsável por dogmatizar os seres em uma subvida contemporânea.

Sendo assim Warat salienta que existem outras máscaras responsáveis pela subversão, desconstrução de padrões, carnavalização e pela abertura ao diferente. Entretanto, a razão fixa limites, leis e normas. Logo, a dialética entre as duas é primordial. Nesse aspecto, Vadinho e Teodoro usam a mesma máscara autoritária, adormecida, que constituem estereótipos da dialética. Não obstante, a perspectiva de abertura de Vadinho permite o abrir-se ao novo, o não ficar fixo em uma máscara.

O discurso jurídico, como máscara autoritária, estereotipa a linguagem em uma censura dos seres, limita a democracia, oculta-a em uma semiologia do poder dominante. Desse modo, a democracia vira totalitarismo. Consequentemente, uma semiologia aberta significa abertura à pluralidade, à multiplicação; ruptura de um simbolismo fechado de signos.

Com efeito, a sociedade burocrática condiciona os seres em uma linguagem política de dominação. A linguagem como meio de supressão dos signos serve de suporte para um mecanismo redutor e ideológico do tecido social. Essa forma de sociedade burocrática precisa dos sistemas simbólicos de reiteração de totalitarismos, a fim de dogmatizar a castração em uma certeza da verdade.

Nesse aspecto, o pensamento contemporâneo do Direito consagra-se por seu positivismo científico, por sua tradição positivista como visão científica da ciência. Como um legado dos rompimentos teleológicos, a racionalidade se define como o logos não advindo de um pressuposto metafísico, mas na razão humana, do pensamento moderno calculador. Nesse sentido, também se define a dogmática jurídica como uma teoria sistemática "del derecho positivo. Sin formular sobre el mismo ningún juicio de valor, convirtiéndola em uma mera ciencia formal” (WARAT, 2004, p. 153).

Assim, Warat crítica a dogmática e a ciência do Direito por postularem um conhecimento supostamente neutro, neutralizado ideologicamente:

Para cumprir com estas funções, o dogmático do Direito constrói um discurso aparentemente científico, mas que, no fundo está prenhe de categorias pseudo-explicativas, que encobrem a cosmologia valorativa com a qual se pretende, no fundo, a reprodução da ordem social. Com seu trabalho, a dogmática consegue, para o Direito, que o valor retórico adquira uma aparência analítica e o interesse uma aparência de legalidade. (WARAT, 2002, p. 42). 
O desvelamento dessa linguagem aparentemente neutra, de ideologias e significações, passa necessariamente por uma edificação de uma consciência crítica, de realidade empírica e linguística. Por este motivo, o conhecimento dogmático parte de um método de conhecimento dedutivo e analítico, de um positivismo funcionalista do fato adequado totalmente à norma. $\mathrm{O}$ divergente, nesse sentido, deve ser enquadrado à norma vigente.

Esse discurso jurídico vigente se apresenta como "el mantenimiento de la racionalidade ideológica, la ausentización de la historia, y el ofrecimiento de um objeto de conocimiento, que se presenta ideologicamente, como um discurso científico, manipulado enteramente por la razón" (WARAT, 2004, p. 157). Essa lógica das contradições privilegia a razão como único instrumento normativo para aplicação da lei. Consequentemente, o jusnaturalismo se infiltra na dogmática e apela à razão para sua expressão.

As concepções dogmáticas positivistas se baseiam em princípios e conceitos que são extraídos do texto legal, do direito posto, dado e escrito. Desse modo, o sistema é regido a partir das normas em que o paradigma da consciência e da representatividade ainda não se desassociou hermeneuticamente do campo epistemológico do direito. "Os juristas não se deram conta do fato de que o direito é linguagem e terá de ser considerado em tudo e por tudo como uma linguagem. [..] E atinge-nos através dessa linguagem que é" (STRECK, 2014, p. 76).

Nesse aspecto, a constituição de sentido da linguagem:

Enquanto uma práxis, é sempre uma práxis comum realizada de acordo com regras determinadas. Estas regras do uso das comunidades linguísticas; são, portanto, costumes que chegam a tornar-se fatos sociais reguladores, ou seja, instituições. Tantas são as formas de vida existentes, tantos são os contextos praxeológicos, tantos são, por consequência, os modos de uso de linguagem, numa palavra, os jogos de linguagem. As palavras estão, pois, sempre inseridas numa situação global, que norma seu uso e é precisamente por esta razão que o problema semântico, o problema da significação das palavras, não se resolve sem a pragmática, ou seja, sem a consideração dos diversos contextos de uso. Poder falar significa ser capaz de inserir-se um processo de interação social simbólica de acordo com os diferentes modos de sua realização (OLIVEIRA, 1993, p. 54).

No plano da hermenêutica, o sujeito moderno do direito não rompeu com o plano da metafísica, reificando-se em uma essência paradigmática, em busca da verdade real/ontológica no campo jurídico. Com efeito, o paradigma aristotélicotomista busca o logos do universal e do abstrato. No positivismo jurídico o real já está dado, posto e enunciado; as indagações do conhecimento já se encontram delineadas pela própria "realidade das ciências, ou seja, as condições do conhecimento só podem 
ser entendidas sob a forma de investigação das regras de constituição e comprovação das teorias no interior de um modelo já consagrado" (WARAT, 2004, p. 54).

Nesse enfoque, a ciência e a linguagem partem de uma molécula do conhecimento que o sujeito analisa o objeto, parte de uma molécula do conhecimento dicotômica, platônica, de separação e análise externa. Em conformidade, o sujeito analisa o objeto, a partir de suas próprias convicções morais. Essa suposta neutralidade do pensamento jurídico dogmático contraria a semiologia, o sistema de signos e a própria noção da linguagem como sistema simbólico.

A partir dessa perspectiva, a linguagem como sistema simbólico é pressuposta de valores que condicionam seu signo. Assim, distanciando-se de uma axiomática cartesiana a noção de valor perpassa uma noção de construção, de história e de sistema. Conforme Aloísio Ruedell (2016), a linguagem é um caminho de percepção da racionalidade humana, pois ela revela o contexto cultural que permeia a sociedade e sua esfera subjetiva; a linguagem revela o habitus e capital que interferem no ser.

A compreensão do discurso, "é sempre a construção de um determinado finito a partir de um indeterminado infinito, pois a linguagem é um infinito, porque são infinitas suas possibilidades de ser determinada por terceiros" (RUEDELL, 2016, p. 36). A hermenêutica como a arte da interpretação, da significação, de compreender o ser, e sua historicidade a partir da linguagem. Essa compreensão, que difere da constatação de significações, infere sentido no ser. Desse modo, o paradigma da linguagem se constitui na busca pelo saber, por uma consciência de si e, principalmente, pelo primado da linguagem, que se constitui na busca de compreender o outro. A linguagem constitui o desafio de compreender o outro.

\section{Verdades absolutas e o imaginário carnavalizado de Warat}

Warat argumenta que a edificação de verdades inquestionáveis cria a unidade como uma forma de dominação, através de uma racionalidade centrada, um logocentrismo totalizador. Por essa razão, o viver em sociedade coletivamente requer uma ordem de intertextualidade, valores, normas que regrem a convivência. O que diferencia as sociedades democráticas e totalitárias, nesse aspecto, é a fixidez ou porosidade da moral.

Nesta perspectiva, o ser humano é considerado como ser social, como ser caminhante e em movimento, que escreve sua história através do tempo e do espaço. Assim, o movimento autêntico é produto de uma simbologia da dominação, esfera em que a própria autenticidade é construção social. Esse ser social, que reitera a produção de um mesmo, fecha-se sobre a realidade de uma ficção objetiva, a-histórica, censurada. Eis que essa ideologia se detém de toda a verdade e origem. A existência, nesse existir censurado, se transforma em subvida, em indivíduos zumbis da norma.

Este pensamento coaduna-se com a abertura de verdades. Tanto o Direito, quanto a Religião, se constituem em mecanismos de linguagem que possuem como 
finalidade perpassar ensinamentos ao longo das gerações e cujo objetivo primordial é ordenar o convívio social. Sob a ótica de filósofos pós-modernistas, como Gianni Vattimo, a busca por conceitos últimos e absolutos é inviável, pois se compreende que a complexidade das relações humanas é tamanha que não se pode conceber com exatidão objetiva os produtos de sua organização social.

Warat propõe uma semiologia do poder, que não se origine de conceitos fechados, logocêntricos, mas de uma racionalidade descentrada, lúdica, poética, diferente, divergente. Essa semiologia, que rompe com os padrões normativos e metafísicos, representa a desconstrução das verdades objetivas, absolutas, tratase de uma proposta democrática, afinal, "não se podem começar uma prática de autonomia sem transgredir essa inocência semiológica” (WARAT, 1990, p. 83). Assim, essa semiologia democrática integra o plural, representa o olhar para as diferenças, para o outro, para o imaginário, que não dogmatiza, mas revela o poder simbólico da linguagem.

Neste sentido, Vattimo (2016) muito tem a contribuir quando defende um adeus a verdades objetivas, totalizadoras, fechadas, e que provêm, impositivamente, de um único paradigma, de um lógos. O autor apresenta a tese de que a verdade como algo absoluto, como correspondência objetiva, é um perigo muito maior que um valor, pois possibilita a imposição de cultura, pensamento, e até mesmo fé sobre aqueles que estão sob o guarda-chuva ou a mira desta verdade, "se não há uma verdade objetivamente dada a alguém de uma vez por todas, em torno da qual se deveriam reunir todos por bem ou por mal, então a verdade nasce e se desenvolve no diálogo" (VATTIMO, 2016, p. 85). O mesmo deve ser dito sobre a "pretensão de conhecer a verdade sobre direitos humanos e inspirar neste conhecimento "verdadeiro" da verdade, uma política de "guerras justas", de intervenções "humanitárias", que não levem em consideração os paradigmas culturais do outro" (VATTIMO, 2016, p. 15).

Principalmente os discursos dogmáticos, enraizados em conceitos totalizantes, fechados, fonocêntricos, castram o erotismo da leitura, censuram a linguagem. Warat (WARAT, 2004, v. 1, p. 117) menciona que Barthes sugere um duplo movimento como forma de reiterar uma prática democrática nas significações; através da resistência e do combate ao poder simbólico totalizante, e da edificação de uma prática linguística a partir de uma racionalidade descentrada. Vattimo (2016, p. 38) apresenta sua hipótese, defendendo que "hoje, na nossa atualidade não apenas filosófica, mas também histórico-social, seja preciso ir além da fenomenologia para uma ontologia da atualidade." Consequentemente, o rompimento com a linguagem centrada é realizado através de uma prática discursiva descentrada. É o primado da sensibilidade, do imaginário, é o rompimento do sentido-centro unitário.

Temos de reinventar a linguagem se queremos desenvolver a democracia. Ela é impossível com homens estereotipados. O homem adormecido, sem efervescência, não é democrático. Um estereótipo não pode portar incertezas, nem aceitar as diferenças e os diferentes (WARAT, 1990, p. 31). 
Esse eterno porvir de uma linguagem não pautada no mesmo ${ }^{4}$ apresenta uma ambivalência que é característica da não fixidez. Desse modo, a ambiguidade da linguagem descentrada representa um caminho para as diferenças, um sair da noite escura totalitária. Assim, o instituído e o autoritarismo são rompidos na luz que a racionalidade descentrada fornece. Warat argumenta que "o surrealismo é um modo de desmantelar as formas de totalitarismo pelo reconhecimento das diferenças" (WARAT, 1990, p. 43), pois rompe com a noção de rebanho, de sujeitos estereotipados que são facilmente controlados.

O imaginário carnavalizado por Warat, nesse aspecto, constitui o rompimento de um centro de sentido que origina todos os sentidos e noções. A linguagem a partir desse rompimento não se origina de um logos, mas permanece plural e divergente, "a magia surrealista é o sonho substituindo os mitos [...] é a magia no lugar da objetividade” (WARAT, 1990, p. 32-33). Esse orgasmo das significações produz o surrealismo no Direito, lugar de erotismo, sensibilidade, ambivalência e de sedução.

Nesse ínterim, a doxa ${ }^{5}$ é uma forma de castração política que através da racionalidade do cotidiano produz uma episteme ideológica de castração, de aprisionamento dentro de si mesmo. Indubitavelmente, desvelar os discursos autoritários e a produção do conhecimento objetivo de verdades significa fragmentar as significações em uma semiologia plural e democrática, em uma carnavalização da epistemologia. Essa polissemia de sentidos apregoa uma ambiguidade inerente ao ser, uma ambiguidade do ser que é dever ser, que é ser sendo e acontecendo ao mesmo tempo.

Falar sobre democracia para Warat implica cingir o diferente, o novo, o inesperado. Significa abrir-se para o outro, em uma dimensão de alteridade e acolhimento; desabrochar-separa odiferentede mim, para oamor. Consequentemente, a linguagem democrática no direito significa abertura à sensibilidade e alteridade no discurso jurídico, expressa o rompimento de padrões dogmatizados e fechados para se dizer o direito, revela a carnavalização como lugar pedagógico da diferença, como pedagogia democrática.

Nesse aspecto, como o lugar pedagógico da diferença, a carnavalização está intrinsecamente vinculada à teoria da complexidade de Edgar Morin. O sujeito em um paradigma complexo cinge as diferenças e as especificidades. Assim, esse sujeito é história, tempo, dinâmica e movimento. A constatação do ser como indivíduo de relações e de laços intersubjetivos quebra com o paradigma moderno das relações.

4 Linguagem proveniente das classificações de Emmanuel Lévinas. "O Outro metafísico é outro de uma alteridade que não é formal, de uma alteridade que não é um simples inverso da identidade, nem de uma alteridade feita de resistência ao Mesmo, mas de uma alteridade anterior a toda a iniciativa, a todo o imperialismo do Mesmo; outro de uma alteridade que não limita o Mesmo, porque nesse caso o Outro não seria rigorosamente Outro: pela comunidade da fronteira, seria, dentro do sistema, ainda o Mesmo. O absolutamente Outro é Outrem; não faz número comigo. A coletividade em que eu digo 'tu' ou 'nós' não é um plural de 'eu'. Eu, tu, não são indivíduos de um conceito comum” (LÉVINAS, 1980, p. 26.).

5 Palavra grega que significa crença comum. Utilizada pelos retóricos gregos como ferramenta para formação de argumentos através de opiniões comuns, a doxa é oposição ao saber verdadeiro, episteme. 
Desse modo, diferente de uma perspectiva comum, a noção do ser em um paradigma complexo possibilita múltiplas ligações entre os indivíduos, uma visão do ser além de verdades absolutas, a visão de ser como ambiguidade, dialética e erotismo.

Para Morin (2015), o pensamento complexo vem para superar os modos simplificadores do conhecimento, que mutilam mais que exprimem as realidades ou os fenômenos de que tratam. Assim, "é complexo o que não pode se resumir numa palavra-chave, o que não pode ser reduzido a uma lei nem a uma ideia simples" (MORIN, 2015, p. 5). Igualmente, a racionalidade que não é mais nascida de um logos "inaugura a destruição, não a demolição, mas a dessedimentação, a desconstrução de todas as significações que brotam da significação de logos. Em especial a significação de verdade" (DERRIDA, 2017, p. 13).

Warat (2004, v. 1, p. 62-63) faz uma associação de Vadinho e Teodoro com a energia feminina e masculina, que integra os indivíduos e forma sua ambiguidade. Assim, Vadinho como sensibilidade e Teodoro como limite edificam esse imaginário de energias contrapostas, mas que edificam a complexidade que é ser sendo e acontecendo. Nesse ponto, Warat critica o saber jurídico posto a partir da modernidade por seu viés preto e branco, ou seja, por seu viés legalista, limitado e masculino, Warat critica a ausência da energia do feminino no direito.

Nessa senda, o pensamento descentrado permite a superação de uma dicotomia onipotente e onipresente no Direito, representa a construção de uma hermenêutica não pautada em um contexto de exclusão. Essa afirmação consiste no desvelamento das estruturas simbólicas de poder e de dominação, no desvelamento de um ser totalizado por uma hegemonia racional. Consequentemente, permite a construção de um viés complexo onto-epistemológico e metodológico que problematiza esquemas de opressão e de igualdade formal, propondo uma reflexão sobre a culturadetergente, que aliena o pensamento em prol de uma masculinidade tóxica e de uma racionalidade opressão de uma semiologia machista, totalitária e de mesmidade.

Por sua vez, esse processo de conhecimento parte de um diálogo de ordem e desordem, da convergência e ambiguidade. Morin fundamenta que essa compreensão de mecanismos dinâmicos e funcionais é como organização ativa, em movimento, plural. Portanto,

Uma ontologia complexa mantém sempre a tensão das polaridades constitutivas do ser, bem como as interações entre as distintas dimensões que o integram com as múltiplas realidades existentes. Nela, ser e realidade emergem juntos. Estão codeterminados em seus processos evolutivos, estruturalmente acoplados e implicados, já que não existe uma realidade independente da natureza subjetiva do ser. Ambos evoluem conjuntamente e se autoeco-organizam a partir de processos de interpenetração sistêmica, em termos de energia, matéria e informação, que nutrem os diferentes fluxos entre o uno e o diverso, entre unidade e diversidade; sujeito, objeto/ realidade. (MORAES, 2015, p. 3-4). 
Com efeito, a partir de ontologia complexa, a procedência do ser humano parte do modo de vir a ser, parte do modo de ser complexo, dinâmico e em movimento, parte de um ser que não pode ser reduzido face a sua multidimensionalidade. Consequentemente, essa formulação de ser multifacetado exige para seu descentramento uma epistemologia complexa, que integre a incerteza, a desordem, a paradoxalidade e o diferente. Desta forma, "é complexo o que não pode se resumir numa palavra-chave, o que não pode ser reduzido a uma lei nem a uma ideia simples" (MORIN, 2015, p. 5). Portanto, a aceitação da complexidade é a aceitação da contradição, e a ideia de que não se podem escamotear as contradições em uma visão otimista ou rasa do mundo. Harmonia e desarmonia estão vinculadas.

"Não existe uma única realidade rede formal de relações, há realidades, que não são essências, que não são uma única substância, são compósitos, produzidos pelos jogos sistêmicos, mas, entretanto, dotados de uma certa autonomia” (MORIN, 2015, p. 49). Isso denota que para cingir uma abertura da linguagem complexa é necessário conceber uma epistemologia de abertura ao sujeito, uma epistemologia de abertura ao conhecimento, desconstrucionista, de infinitude, de rompimento com uma ontologia totalitária.

A censura que a linguagem da totalidade reverbera engloba a dominação simbólica sobre os corpos. A palavra como produção de significados, como sistema simbólico conduz a uma consciência provocativa, que no caso do direito, é uma consciência aniquiladora das diferenças. A totalidade, nesse sentido, é a realização. Da dinâmica do Mesmo, a síntese:

Final das energias que integram o Outro a uma unidade sólida. No sentido de ser uma síntese final, a totalidade é também finita. A totalidade abriga em si seu sentido finito, seu sentido ontológico, uma vez que ser e totalidade se conjugam (sic.) em uma unidade fática. A intotalidade, infinitude da totalidade, significa incompletação, suspensão da dinâmica de completação, negação do encontrar-se consigo mesmo ínsito a todo processo de totalização possível. (SOUZA, 2018, p. 111).

Desse modo, esse eu egocêntrico explana a racionalidade jurídica em uma linguagem colonizadora de significados. Essa racionalidade jurídica ontológica induz o desejo a uma cultura do imobilismo, a uma linguagem objeto excessivamente racional, em uma forma de pensar colonizadora, eurocêntrica e egocêntrica. Conforme predissera, essa "pretensão totalizante do direito exclui, marginaliza e oprime aqueles que nela não se encaixarem" (CRUZ; SILVA, 2018, p. 51).

Nesses termos, esse sujeito solipsista, que a racionalidade jurídica reitera, produz o direito a partir de si mesmo, de uma racionalidade centrada e logocêntrica da lei. Com efeito, a hermenêutica como uma questão moderna mantém na figura de um discurso objetivo, uma aposta solipsista, lastreada em um paradigma racionalista subjetivista. Esse paradigma instrumentalista, que determina a neutralidade de uma 
racionalidade essencialista, aristotélica, tomista, reflete uma racionalidade dada, posta, literal ao disposto na lei.

Assim, esse sentido político da cientificidade dos discursos jurídicos revela um saber jurídico logocêntrico, pautado em uma razão instrumental da linguagem. Esse controle epistêmico da linguagem pelo direito traduz-se uma totalidade ontológica, em que a produção do signo ideológico é o reflexo de uma ortodoxia epistemológica, ou seja, de um conhecimento científico que apenas produz conceitos e não significações, sintetizando um enclausuramento lógico de uma perspectiva metodológica e epistemológica logocêntrica e totalizadora.

\section{A compreensão de gênero como porvir aberto}

Pensar gênero complexamente, principalmente em uma abordagem dialética e histórico-estrutural ${ }^{6}$, requer um pensar através de uma perspectiva ontológica, epistemológica e metodológica. Assim pretende-se compreender gênero em um olhar complexo-paradoxal, não apenas interpretativo ou analítico, mas que atente para as contradições, as oposições e os paradoxos que pressupõem a palavra gênero. "O pensamento complexo é o pensamento que se esforça para unir, não na confusão, mas operando diferenciações" (MORIN, 2010, p. 33).

Esse horizonte reflexivo, que também integra um olhar crítico-dialético emancipador, tem por condão introduzir uma dinâmica aberta na compreensão, sem feições redutoras nem totalizadoras. Assim, emerge desse pensamento não uma interpretação unificadora dos sentidos e das significações, mas um pensar complexo e dialético, em movimento, dinâmico, histórico e temporal.

Compreender a noção gênero em uma dinâmica aberta, não reduzindo a palavra gênero meramente a uma categoria analítica ou apenas a partir de uma abordagem hermenêutico-fenomenológica, significa compreender gênero em uma dimensão aberta de sentidos e significações, em um eterno ser e devir. "A ideia de interação contínua entre os diversos elementos/componentes de um sistema nos leva à dialógica. As relações que se estabelecem dentro de uma relação recursiva serão ao mesmo tempo complementárias, convergentes e antagônicas" (SANCHEZ, 2010, p. 174). Uma dimensão que não permanece fixa, mas aberta a novas compreensões e paradoxos, em uma linguagem dinâmica:

O conceito de sistema aberto tem valor paradigmático. Como observa Maruyama, conceber todo objeto e entidade como fechados implica uma visão de mundo classificadora, analítica, reducionista, numa causalidade unilinear. Foi exatamente essa visão que se instaurou na física do século XVII ao XIX, mas que hoje, com os aprofundamentos e os avanços rumo à complexidade,

6 Abordagem que possui como viés crítico a emancipação, caminhando por processos históricos em uma visão dinâmica e conflitiva da realidade. 
vaza por todos os lados. Trata-se de fato de operar uma reversão epistemológica a partir da noção de sistema aberto. As pessoas vivem no universo classificatório agem com a percepção de que todo sistema é fechado, a menos que ele seja especificado de outro modo. (MORIN, 2015, p. 23).

Nesse viés a episteme complexo-paradoxal percebe gênero longe de perspectivas dicotômicas do sujeito e do objeto, mas a partir de uma perspectiva caminhante e interconexa. Significa compreender gênero, como já foi dito anteriormente, como um resultado de um paradoxo intersubjetivo através de um entendimento ampliado. Desse modo, o sujeito integra o objeto e o objeto integra o sujeito. A relação social forma múltiplas relações entre os seres que se autoconfrontam e se autorrefletem. Consequentemente, esse viés integra uma abordagem ontológica complexa por cingir as diversas interconexões e interrelações da relação do sujeito com o objeto.

Ao defender o surrealismo e o olhar carnavalizado, Luis Alberto Warat nos convida a tomar outra posição frente ao objeto, que pode ser o saber jurídico, a democracia, os papéis sociais estereotipados impostos. $\mathrm{O}$ autor ainda demonstra a necessidade de deixar a arquibancada, a compreensão ótica, com o intuito de nos misturarmos ao objeto, "trata-se de uma imaginação que recupera o mundo como criatividade e como resistência, solicita a intervenção ativa e emancipatória do homem, decretando com isso a morte do pensador-voyeur" (WARAT, 1990, p. 22-23).

Por seu turno, gênero como identidade construída culturalmente, produto das práticas sociais e individuais, significa uma forma de estar e ser no mundo, significa uma visão de ser que é empírica. Assim, gênero é uma maneira de estar no mundo, de se conceber como pessoa. Esse enfoque possibilita a desconstrução dos esquemas deterministas e biológicos da formação das identidades, desconstrução de gênero como uma consequência mecânica de ideologias e práticas sociais, desconstrução do corpo como uma superfície neutra, lugar de depósito de ideias, de representação e de símbolos:

Por tanto, la heterosexualidad y/o la oposición masculino/ femenino pueden ser, son de hecho para muchas mujeres (y hombres) instrumento identitarioy mecanismo de subordinación, pero pueden ser también herramientas al servicio del deseo y la interacción. Begoña es muy crítica con la clasificación de hetero/ homo/bisexualidad, por el binarismo que implica, en la medida que son combinaciones de dos posibilidades que se presentarían como incuestionadas e incuestionables, y porque en definitiva condiciona una manera bipolar, bi-sexual, de entender las relaciones entre los humanos. (GALARZA, 2008, p. 38).

Essa característica multidimensional da palavra gênero rompe com um plano de constituição dicotômica do ser, proveniente de Platão, que separava o mundo 
das ideias, perfeito, do mundo físico, imperfeito. Esse rompimento proveniente de um descentramento do logos epistemológico proporciona um olhar para as diferenças, o plural, um olhar diversificado. A partir desse pensamento descentrado, surrealista, a matriz heterocêntrica é questionada em virtude de seu olhar unificador. O descentramento necessariamente representa o rompimento de padrões, o questionamento de ideias totalitárias, para produzir possibilidades emancipatórias.

Apelando para as possibilidades emancipatórias do pensamento mágico, o surrealismo procura substituir esse amor enfermo pela procura da afirmação de nossa singularidade. Para isso, tenta subverter a figura perfeita da lei, da ciência e do poder, descobrindo-lhes certas marcas de corrupção; tenta inventar uma contra-imagem dos objetos amados. Um desencanto que nos permita recuperar nossa autonomia. Assim, deixaríamos de idealizar essas figuras, redescobrindo-as em suas imperfeições, e, portanto, em sua história real (WARAT, 1990, p. 34).

Com efeito, esse ser que é, ao mesmo tempo sendo e acontecendo, na teoria da complexidade é visto a partir de um todo unitário, porém aberto, dinâmico, histórico. Em outras palavras, a partir da teoria das múltiplas dimensões integradas, o ser é compreendido em toda sua extensidade e complexidade, rompendo com a teoria dualista da matéria. $\mathrm{O}$ rompimento da ordem por natureza também rompe com ideologias absolutistas e totalidades, que apregoam um ideal fechado, fixo e atemporal. Assim, gênero como esse ser que é ao mesmo tempo sendo e acontecendo, representa o processo identitário de reconhecimento de sua identidade, de construção emancipatória do sujeito. Representa o processo de abertura que o presente estudo conceitua como esse Outro, que não tem forma nem padrão, mas o Outro que eu acolho a minha morada, gênero representa, nesse sentido, acolhimento.

Desse modo, resultado da complexidade, a ambiguidade diante das estruturas, como unidade de contrários e seus encaixes não suprimem os graus de liberdade da dinâmica frente ao todo. Esse todo não assume posturas lineares, tendo como característica processos evolucionários e históricos. Diante desses processos a ambivalência também se faz presente. A força de polos contrários não se resume em um conflito em si, mas na característica não linear da complexidade.

Com efeito, perante um pensamento desconstrucionista e de abertura, Emanuel Lévinas fornece subsídio a um pensar crítico e ético diante das estruturas de poder e de submissão. Lévinas pontua a necessidade de abertura ao vazio erótico ${ }^{7}$ a um discurso democrático, a um ser não totalizado, significa abraçar o erotismo como significado, abraçar o erotismo ${ }^{8}$ como didática. Nesse sentido, representa o cingir da ambivalência da ordem e da desordem que constituem o ser, a desconstrução do

7 Conforme Warat o vazio erótico é o se despir das verdades absolutas para ir de encontro ao Outro. Despir-se das verdades absolutas para dialogar, buscar o saber.

8 Concepção de Warat que simboliza o despir-se das verdades absolutas. 
sistema simbólico da castração, do sistema opressor, do paradigma da masculinidade tóxica, de uma hegemonia racional, de lugares ao feminino e ao masculino, tanto no plano simbólico como nos espaços sociais destinados a cada ser. Consequentemente, a partir da desconstrução desse ser castrado pelo humanismo moderno, é possível desvelar o sentido político da cientificidade dos discursos simbólicos da mesmidade.

O sair de si e a alteridade significam a possibilidade de interpelação. É uma abertura para aquele que chega, que não pode ser assimilado ou ser sentido (COSTA, 2008). Por derradeiro, a racionalidade descentrada representa um lugar da face humana que a origem não é predefinida por um logos. Indubitavelmente, a ética proposta por Lévinas representa uma desconstrução de uma racionalidade a qual apregoa uma existência independente e um processo de identificação logocêntrico, fonocêntrico.

Essa relação que é comunicação, linguagem, diferença e proximidade, não é uma relação de compreensão. Para Lévinas (1980), não há como compreender totalmente o Outro sem anular sua subjetividade, sua individualidade, sua diferença. Essa relação que representa uma abertura de vir a ser, significa o abrirse para a face do desconhecido. Com efeito, essa abertura permite uma inquietante aproximação, estranhamento e uma captação pelo olhar de ser, não transformado em Mesmo (SOUZA, 2018). Warat (1990) argumenta que não existe prática coletiva emancipatória se não reconhecermos que nossos desejos também são fundamentais, de modo que há necessidade de interconexão entre macroexperiências libertárias e microexperiências desejantes.

Para Lévinas, o processo interacional do sair de si, do rompimento do fechar-se sobre si, é um caminho sem voltas, no qual "a constituição de identidade é permanente, contínua e resultante, principalmente, do contato com o rosto do outro" (MOURA, 2013, s. p.). Warat também defende a não transformação do Outro em Mesmo, ao dizer "os outros não são nossos semelhantes, são nossos diferentes” (WARAT, 1990, p. 43). Em outras palavras, a sensibilidade, para Lévinas, é o componente ético que apregoa um sentido moral de justiça. Logo, na relação com o Outro há uma abertura para o diferente, um movimento de responsabilidade ao e pelo rosto do Outro.

Essa relação de responsabilidade pelo Outro, pelo processo de acolhimento do Outro, tematizada por Lévinas (1980) como a figura do feminino. Figura que não tem forma, que representa o ser que acolhe. Por conseguinte, o feminino em Lévinas não tem gênero, representa o ser que acolhe, que convida a minha morada, sendo o feminino simbólico. O Outro face à ação de responsabilidade, ao olhar de alteridade, é tematizado como diferença.

Consequentemente, o processo de acolhimento levinasiano independe do gênero, e do processo de identificação pessoal, o qual deve ser acolhido independentemente de sua diferença, de suas individualidades e especificidades (LÉVINAS, 1980). Aqui, pontua-se o entendimento de gênero como processo identitário de acolhimento, processo de abertura ética para com o Outro, processo de acolhimento e de alteridade. 
Neste cenário, a violência da redução do Outro ao Mesmo revela um aprisionamento do corpo frente a uma matéria, a um sentido racional e dicotômico de pensar o ser. Pensar em gênero de forma totalitária reflete nessa desumanização do Outro, do não ouvir de sua alteridade. Partindo de um viés logocêntrico e ontológico, a compreensão do humano dualista advém de um viés apenas. Em síntese, parte de uma objetificação do ser diante de um Mesmo, um olhar ontológico. Dessa forma, o pensamento que rompe com o ideal de ser pautado em um Mesmo possibilita esse olhar para o diferente, para aquele que não pode ser compreendido na sua totalidade.

Nessa perspectiva, o olhar metodológico para o ser em movimento abre uma dimensão fenomenológica para o diferente, possibilita a abertura de uma dimensão do não encastelamento sobre si. Por conseguinte, abre caminhos para uma ética que não se concentra em uma racionalidade fechada e absoluta, mas em uma ética caminhante e contínua. Uma ética que não reduz o ser em conceitos universais, mas abre caminhos para um refletir sobre a verdadeira vida, a vida pulsante, a vida que está fora do fechamento sobre si.

E, a partir desse viés teórico da sensibilidade, de compreender o ser humano a partir de suas múltiplas dimensões, é possível conceber que o humano é muito mais que a concepção dualista de matéria, ou seja, é entender que o ser é muito mais que corpo e alma. Consequentemente, cingir a unicidade do ser significa descortinar os entendimentos que o reduzem a um ser simplista, e compreendê-lo a partir de suas diferenças, especificidades, singularidades e desejos do Outro.

"Padrões de gênero podem ser radicalmente diferentes entre contextos culturais distintos, e há certamente muita variedade entre maneiras de pensá-los, mas ainda é possível pensar (e agir) entre culturas em relação ao gênero" (CONNELL; PEARSE, 2015, p. 49). A partir do simbolismo, da cultura e do discurso, gênero é entendido numa dimensão de ser que integra múltiplas dimensões integradas. Consequentemente, esse ser que é único e individual, também é político, moral, histórico, transcendental, social, desejante, terreno, religioso e cultural.

Essa noção de ser que integra o vir a ser, também integra um conceito estrutural. Inegável que estruturas embasam e edificam lentes de se ver o mundo, entretanto essas estruturas também são dinâmicas (DEMO, 2002). Por derradeiro, por não ser uma estrutura totalmente fixa, é dinâmica e mutável:

Precisamos rejeitar o caráter fixo e permanente da oposição binária, precisamos de uma historicização e de uma desconstrução autênticas dos termos da diferença sexual. Temos que ficar mais atentas às distinções entre nosso vocabulário de análise e o material que queremos analisar. Temos que encontrar os meios (mesmo imperfeitos) de submeter, sem parar, as nossas categorias à crítica, nossas análises à autocrítica. Se utilizarmos a definição da desconstrução de Jacques Derrida, esta crítica significa analisar no seu contexto a maneira como opera qualquer oposição binária, revertendo e deslocando sua construção hierárquica, em lugar de 
aceitá-la como real, como óbvia ou como estando na natureza das coisas. (SCOTT, 1990, p. 26).

Ao romper com a ordem por natureza, a cultura e a linguagem fazem parte da constituição de ser. O rompimento com a ordem por natureza também é, consequentemente, a ruptura com ideologias absolutistas e totalidades, que apregoam um ideal fechado, fixo e atemporal. Assim, gênero como esse ser que é ao mesmo tempo sendo e acontecendo representa o processo identitário de reconhecimento de sua identidade. Representa o processo de abertura que o presente estudo conceitua como esse Outro, que não tem forma nem padrão, mas o Outro que eu acolho a minha morada, gênero representa, nesse sentido, acolhimento.

Os espaços negados de um gênero não integrado partem de pressupostos metafísicos, de sistemas de crenças e de juízos de valor de uma racionalidade do cotidiano. Assim, a igualdade abstrata da lei cinge os iguais na medida de sua diferença, na medida de seu padrão, mede a diferença a partir da sua, ou seja, é estabelecido um centro-sentido, padrão universal para legitimar essa igualdade, a definir o que se entende por dignidade humana. É exatamente essa moral fundamentada em um SiMesmo que reproduz o sistema de crenças e sentimentos em uma ordem simbólica totalizada. Nesse sentido, a violência do Mesmo refere-se à violência da perspectiva dicotômica, na redução contemplativa, na não significação dos seres (HAN, 2017). Consequentemente, a moral como referente normativo da estrutura social orienta e justifica a violência por meio da racionalidade.

Nesse sentido, Linda Nicholson (1999) rotula essa definição do corpo como interpretação social contraposta entre feminino e masculino como "fundamentalismo biológico” (NICHOLSON, 1999, p. 4). Assim, as diferenças entre os seres justificam o determinismo biológico, na medida em que o que é natural e dado não pode ser transformado, criado, editado. Aqui, citam-se fontes do determinismo biológico e do desenvolvimento da compreensão de cultura.

De fato, os antecedentes históricos da concepção do termo cultura já perpassaram compreensões biológicas e de natureza. Entretanto, na desconstrução de uma percepção linear e limitada, o conceito de cultura se desenvolveu multilinearmente (LARAIA, 2001, p. 14). Dessa forma, Nicholson salienta que a diferença do fundamentalismo biológico e do determinismo biológico se concentra na inclusão de elementos de construcionismo social, porém elementos limitados e problemáticos, que se vislumbram como na narrativa "nasceu em corpo errado" (BRASIL, 2017, p. 8).

Sob este aspecto, essa abordagem dualista de construtivismo social obscurece a possibilidade da diferença, das especificidades e das divergências. Quando o centrode-sentido permanece comum, central originário, a diferença é anulada em prol de uma igualdade formal, de uma igualdade que parte de um pressuposto metafísico de origem-centro. A diferença, nesse sentido, existe em todos os átomos do corpo 
humano, o modo de agir, sentir, reconhecer; a diferença perpassa vários sentidoscentros, que apenas uma racionalidade descentrada consegue diferir.

Com efeito, é necessário problematizar a linguagem e sua simbologia como sistema simbólico de construção de sentido. É necessário analisar criticamente a moral que condiciona a linguagem a partir de um viés de dominação masculina. É necessário problematizar a linguagem moralmente normatizada que produz e reproduz mais do Mesmo, a linguagem do Eu e da objetificação. A linguagem que não fere fisicamente, mas que interfere na construção das subjetividades do indivíduo.

\section{Considerações finais}

A análise literária da obra A Ciência Jurídica e seus Dois Maridos fornece subsídio para se pensar a realidade como modo de vir a ser, como sujeito que analisa o objeto, mas também analisa a si mesmo. Precipuamente, diante do senso comum teórico dos juristas, verdades absolutas são enraizadas de dogmas, em uma crença no determinismo universal no Direito. Nessa perspectiva, a carnavalização proposta por Warat significa o pensar o direito como ambiguidade, lugar de incertezas, possibilidades e, principalmente, da diferença.

Observa-se, que a dimensão política da linguagem influencia no poder do discurso. O dogmatismo jurídico evidenciado revela a totalização e normatização da linguagem, que, sob a ótica positivista-funcionalista, adequa o fato à norma em uma suposta inocorrência subjetiva. Assim, o direito, como essência política, revela sua não neutralidade e o poder simbólico de sua linguagem política e totalitária.

Warat postula que os dogmas das verdades inquestionáveis, das verdades absolutas, são mantidos e reiterados através da semiologia dominante, que, através de sua linguagem metafísica, reitera e reifica a linguagem, estabelecendo padrões e hierárquicas. Assim, a edificação de verdades inquestionáveis cria a unidade como uma forma de dominação, através de uma racionalidade centrada, de um logocentrismo totalizador. Consequentemente, esse movimento autêntico do direito é produto de uma simbologia da dominação, em que a própria autenticidade se constrói socialmente.

Por seu turno, esse movimento logocentrista do positivismo jurídico revela uma semiologia pautada em uma linguagem de dominação, uma semiologia representada em um senso comum no discurso jurídico. Com efeito, esse referencial logocêntrico da epistemologia jurídica estereotipa a linguagem em uma supressão de signos ideológica. Desse modo, o tecido social no direito é totalizado em uma fixidez aparente da norma, em uma linearidade não dialética da norma.

Trata-se de uma linguagem objeto do pensamento moderno, que apregoa a racionalidade como único logos, referencial sentido centro de todos os sentidos e noções no direito. A hermenêutica do direito como uma questão moderna se mantém na racionalista tomista aristotélica, de uma razão instrumental e objetiva. Assim, 
a seguir, esse critério de decidibilidade é ligado ao dogmatismo da verdade. Nesse percurso, se dialoga com o critério de decidibilidade no direito e com a mesmidade de uma metalinguagem. Além disso, Warat discorre sobre função política do discurso jurídico em virtude de uma imprescritível formação social. Isso significa que a semiologia jurídica possui uma dimensão ideológica de significação. A coerência, clareza e inteligibilidade cumprem funções políticas, simbólicas nessa hermenêutica do direito.

Ao percorrer o caminho de compreensão da ambiguidade da lei através do lúdico, da poesia, Warat nos dá suportes para questionar as verdades totalizantes. Assim, o imaginário carnavalizado torna-se ferramenta para questionar verdades objetivas, absolutas, para pensar em uma ontologia da atualidade frente a uma ontologia essencialista. Neste sentido, a compreensão do gênero pode ser vista como um porvir, uma abertura, desvelar-se para ver o rosto do Outro. O pensamento surrealista waratiano contribui na construção de um pensamento de aberturas, de um olhar complexo que compreende a importância da diferença e das ambiguidades.

A constituição de processos de abertura e dinamicidade representa expressões de se ver e conceber o mundo e a realidade como vir a ser. Esse conjunto de ferramentas e mecanismos complexo-paradoxais ressignificam os espaços contraditoriamente opressivos e performativos. Assim, os rompimentos de paradigmas dicotômicos e dualistas perpassam um pensamento não linear, dialético, histórico-estrutural do ser que é histórico, temporal e dinâmico. O olhar surrealista é um chamamento para uma cultura emancipatória, de valorização da autonomia, mas, também, de valorização da relação com o Outro.

A censura, que a linguagem da totalidade reverbera, engloba a dominação simbólica sobre os corpos. A palavra, como produção de significados, sistema simbólico, conduz a uma consciência provocativa que, no caso do Direito, é aniquiladora das diferenças. Essa racionalidade jurídica ontológica induz o desejo a uma cultura do imobilismo, a uma linguagem do objeto excessivamente racional, a uma forma de pensar colonizadora, eurocêntrica e egocêntrica. Assim, esse sentido político da cientificidade dos discursos jurídicos revela um saber jurídico logocêntrico pautado em uma razão instrumental da linguagem.

\section{Referências}

AGUIAR, R. A. Alteridade e rede no direito. In: COSTA, A. B. (Org.). O Direito achado na rua: nossa conquista é do tamanho da nossa luta. Rio de Janeiro: Lumen Juris, p. 5-48, 2017

ARENDT, H. Origens do totalitarismo: antissemitismo, imperialismo, totalitarismo. São Paulo: Companhia das Letras, 2013. 
BERGER, P. L; LUCKMANN, T. A construção social da realidade: Tratado de Sociologia do Conhecimento. 36. ed. Trad. Floriano de Souza Fernandes. Petrópolis: Vozes, 2014.

BOURDIEU, Pierre. O poder simbólico. Tradução de Fernando Tomaz. Rio de Janeiro: DIFEL, 1989.

BRASIL. Tribunal de Justiça do RS, Sexta Câmara Criminal. Agravo em Execução no 70075128587. Relatora: Vanderleia Teresinha Tremeia Kubiak. Rio Grande do Sul, 2017.

BUTLER, Judith. A vida psíquica do poder: teorias da sujeição. Belo Horizonte: Autêntica, 2018.

BUTLER, J. Problemas de Gênero: feminismo e subversão da identidade. Tradução Renato Aguiar. 13. ed. Rio de Janeiro: Civilização Brasileira, 2017.

CITELLI, A. Linguagem e persuasão. São Paulo: Ática, 2007.

CONNELL, R.; PEARSE, R. Gênero: uma perspectiva global. São Paulo: Versos, 2015.

COSTA, José André da. Crítica ao modelo moderno de subjetividade: a proposta de subjetividade no pensamento de Levinas. In: CARBONARI, Paulo (Org.). Ética, educação e direitos humanos: estudos em Emmanuel Levinas. Passo Fundo: Instituto Superior de Filosofia Berthier, 2008.

DEMO, Pedro. Introdução à sociologia: complexidade, interdisciplinaridade e desigualdade social. São Paulo: Atlas, 2002.

DERRIDA, Jacques. Gramatologia. 2. ed. São Paulo: Perspectiva, 2017.

GALARZA, Mari Luz Esteban. Identidades de género, feminismo, sexualidad y amor: loscuerpos como agentes. In: Política y Sociedad, v. 46, n. 1 e 2, 2009, p. 27-41. Disponível em: https://core.ac.uk/download/pdf/38818731.pdf. Acesso em: 20. jun. 2020.

HAHN, Noli Bernardo. O pensamento desconstrucionista e descentrado de Jacques Derrida: um desafio epistemológico no combate a fundamentalismos e totalitarismos. Revista Videre. v. 10. n. 20. Jul./Dez., p. 76-87, 2018. Disponível em: https://ojs.ufgd. edu.br/index.php/videre/article/view/7543. Acesso em: 20 abr. 2021.

HAN, B. Topologia da violência. Petrópolis: Vozes, 2017.

LEVINAS, Emmanuel. Totalidade e infinito. Tradução de José Pinto Ribeiro. Lisboa: Edições 70, 1980. 
MORAES, Maria Cândida. Da ontologia e epistemologia complexa à metodologia transdisciplinar. In: Terceiro Incluído. Dossiê ECOTRANSD. Ecologia dos saberes e transdiciplinaridade. NUPEAT-IESA-UFG, v.5, n.1, Jan./Jun., 2015, p. 1-19. Disponível em: https://www.revistas.ufg.br/teri/article/view/36344. Acesso em: 22 mai. 2020.

MORIN, Edgar. Introdução ao pensamento complexo. Trad. Eliane Lisboa. 5. ed. Porto Alegre: Sulina, 2015 .

MOURA, Rafael. Soares. Justiça e alteridade: a hermenêutica jurídica pautada na ética do amor. Belo Horizonte: Initia Via. Livro Digital, 2013.

NICHOLSON, L. Interpretando o gênero. Tradução Luiz Felipe Guimarães Soares. Revista Estudos Feministas, Florianópolis, v. 8, n. 2, 2000. Disponível em: <https:// periodicos.ufsc.br/index.php/ref/article/view/11917/3846o >. Acesso em: 26 jun. 2019. p. 9-41.

RUEDELL, A. Hermenêutica: da necessidade de interpretar para um modo de pensar. - Ijuí: Unijuí, 2016.

SAFFIOTI, H. Gênero, patriarcado e violência. São Paulo: Fundação Perseu Abramo, 2004 .

SCOTT, J. W. Gênero: uma categoria útil de análise histórica. Educação e Realidade, vol. 16, no 2, Porto Alegre, jul./dez. 1990, p.5. Disponível em: https://seer.ufrgs.br/ educacaoerealidade/article/view/71721/406677>. Acesso em 25 mar. 2019.

SOUZA, Ricardo Timm. Ética do escrever: Kafka, Derrida e Literatura como crítica da violência. Porto Alegre: Zouk, 2018.

STEIN, E. A questão do método na filosofia: um estudo do modelo heideggeriano. 3. ed. Porto Alegre: Movimento, 1991.

STRECK, L. L. Hermenêutica jurídica em crise: uma exploração hermenêutica da construção do Direito. Porto Alegre: Livraria do Advogado, 2018.

SUNG, J. M. Sujeito e sociedades complexas: para repensar os horizontes utópicos. Petrópolis: Vozes, 2002.

SYTIA, C. V. M. O direito e suas instâncias linguísticas. Porto Alegre: Fabris, 2002.

VATTIMO, Gianni. Adeus à verdade. Petrópolis: Vozes, 2016. 
WARAT, Luis Alberto. Territórios desconhecidos: a procura surrealista pelos lugares do abandono do sentido e da reconstrução da subjetividade. v. 1. Florianópolis: Fundação Boiteux, 2004.

WARAT, Luis Alberto. Territórios desconhecidos: o sonho acabou. v. 2. Florianópolis: Fundação Boiteux, 2004

Recebido em 04/08/2020.

Aceito em 21/04/2021. 